\section{The Influence of Substrate Hydraulic Conductivity on Plant Water Status of an Ornamental Container Crop Grown in Suboptimal Substrate Water Potentials}

\author{
Jeb S. Fields and James S. Owen Jr. ${ }^{1}$ \\ Hampton Roads Agricultural Research and Extension Center, Virginia Tech, \\ 1444 Diamond Springs Road, Virginia Beach, VA 23455
}

\section{Holly L. Scoggins \\ Department of Horticulture, Virginia Tech, 306 Saunders Hall, Blacksburg, VA 24061 \\ Additional index words. pine bark, coir, sphagnum peatmoss, irrigation, water stress, Hydrangea arborescens 'Annabelle'}

\begin{abstract}
Many soilless substrates are inefficient with regard to water (i.e., high porosity and low water holding capacity), which provides an excellent opportunity to increase water efficiency in containerized production. We suggest that increasing hydraulic conductivity in the dry range of substrate moisture content occurring during production can increase water availability, reduce irrigation volume, and produce high quality, marketable crops. Three substrates were engineered using screened pine bark (PB) and amending with either Sphagnum peatmoss or coir to have higher unsaturated hydraulic conductivity between water potentials of -100 and $-300 \mathrm{hPa}$. There was no correlation between substrate unsaturated hydraulic conductivity and saturated hydraulic conductivity ( $r=0.04, P=0.8985)$. Established Hydrangea arborescens (L.) 'Annabelle' plants were grown in the three engineered and a conventional (control) PB substrates exposed to suboptimal irrigation levels (i.e., held at substrate water potentials between -100 and $-300 \mathrm{hPa}$ ) for 32 days. The plants in the engineered substrates outperformed the control in every growth and morphological metric measured, as well as exhibiting fewer (or no) physiological drought stress indicators (i.e., vigor, growth, plant development, etc.) compared with the control. We observed increased vigor measures in plants grown in substrates with higher unsaturated hydraulic conductivity, as well as greater plant water uptake. The coir increased unsaturated hydraulic conductivity and provided an increased air space when incorporated into coarse bark vs. if peat was incorporated into bark at the same ratio by volume. Increasing PB hydraulic conductivity, through screening bark or amending bark with fibrous materials, in concert with low irrigations can produce marketable, vigorous crops while reducing water consumed and minimizing water wasted in ornamental container production.
\end{abstract}

\footnotetext{
Received for publication 31 Mar. 2017. Accepted for publication 29 June 2017.

Funding for this work was provided in part, by the Virginia Agricultural Experiment Station and the Hatch Program of the National Institute of Food and Agriculture including the Specialty Crop Research Initiative Project Clean WateR ${ }^{3}$ (2014-51181-22372), the U.S. Department of Agriculture.

This article is a portion of a dissertation submitted by Jeb $\mathrm{S}$. Fields to fulfill requirements of $\mathrm{PhD}$ degree.

We thank James Altland, Marc van Iersel, and Joshua Heitman for their comprehensive reviews. We would also like to thank Pacific Organics and FibreDust, LLC for contributing substrate supplies to this study. Mention of a trademark, proprietary product, or vendor does not constitute a guarantee or warranty of the product by Virginia Tech and does not imply its approval to the exclusion of other products or vendors that also may be suitable. ${ }^{1}$ Corresponding author. E-mail: jsowen@vt.edu.
}

Fresh water is a limited resource that is necessary for the production of all plants. Forty percent of freshwater withdrawn in the United States is used for irrigation of crops (Kenney et al., 2009). Furthermore, plants in intensively controlled container production systems must receive quality fresh water daily or multiple times per day, in the absence of precipitation, to prevent actual or perceived plant water stress. Because of this, growers often apply excess water to container crops to alleviate concerns of underwatering that could render the plant unmarketable or delay time to sale (Mathers et al., 2005). This has led to container nurseries applying upward of $180 \mathrm{~m}^{3}$ of irrigation per hectare per day during the warm season (Fulcher and Fernandez, 2013). With potential future water restrictions, growers will have to adopt more sustainable cultural practices to thrive.
Most container nurseries use overhead irrigation on all or a portion of their operation and may not have the infrastructure to switch to more sustainable irrigation systems (Beeson et al., 2004). Therefore, growers must expand their efforts beyond irrigation technology to increase water sustainability (Fulcher et al., 2016). One area where growers can make modifications that provide potential water savings, without additional infrastructure, is selecting more sustainable soilless substrates (Barrett et al., 2016). Substrates with increased sustainability would include those that increase water storage capacity or more effectively deliver stored water to the plant. Conventional soilless substrates were initially developed to provide growers with increased control over the container system. Substrates are highly porous so that they drain rapidly, prevent salt stress, and are initially pathogen-free (Raviv and Lieth, 2008). Furthermore, these substrates were developed to allow containers to receive excess water from precipitation without concerns of flood stress as observed in some mineral soils. As a result, the current best management practices (BMPs) for container nursery production recommend maximum water holding capacity or container capacities (CCs) $>45 \%$ and air spaces (ASs) $<30 \%$ of the container volume ( $45 \%$ to $65 \%$ by vol. and $10 \%$ to $30 \%$ by vol., respectively; Bilderback et al., 2013). These increased AS values, compared with a field soil, allude to the primary focus of substrate design being able to release water as opposed to water retention or storage. Furthermore, conventional wisdom based on past research infers that the degree of water availability has strict cutoffs of easily available water [between -10 and $-50 \mathrm{hPa}$ substrate water potential $(\Psi)]$ and water buffering capacity ( $\Psi$ between -50 and $-100 \mathrm{hPa}$ ), with all water held at $\Psi<-100 \mathrm{hPa}$ not readily accessible to plants (de Boodt and Verdonck, 1972; Pustjarvi and Robertson, 1975). We believe substrates should provide a better balance of sufficient drainage and water retention. Such substrates should retain water during and after irrigation events to reduce the volume of water required to grow containerized crops.

As substrate science develops, understanding more about using dynamic hydraulic properties as measures of substrate productivity as it relates to resource (i.e., water and mineral nutrient) sustainability is becoming imperative (Caron et al., 2014). For example, moisture characteristic curves (MCC) provide information on dynamic hydraulic properties that depict the relationship between volumetric water contents (VWCs) and $\Psi$ (Bunt, 1961). Better defining the relationship between hydraulic conductivity $(K)$ and $\mathrm{MCC}$ provides information on substrate environmental sustainability (through increased resource retention; Naasz et al., 2005) and water availability (O'Meara et al., 2014).

While the relationships between substrate $K$ and $\Psi$ or VWC are not commonly measured, saturated hydraulic conductivity $\left(K_{\mathrm{s}}\right)$ is increasingly used. Concurrent work by the 
authors demonstrated little correlation $(r=-0.32$, $P=0.1536)$ between optimal production $K$ $(\Psi=-75 \mathrm{hPa})$ and measured $K_{\mathrm{s}}$ for barkbased substrates (Fields, 2017). This is due to $K$ being a limiting factor for water uptake by roots in soilless substrates (Raviv et al., 1999) and field soils (Campbell and Campbell, 1982). Historically, unlike $K_{\mathrm{s}}$, unsaturated $K$ has been difficult to accurately measure (Raviv et al., 1999). However, measuring substrate $K$ can aid in irrigation decisions and help reduce water stress in container production (da Silva et al., 1993). Therefore, using more recently developed substrate hydraulic property measurements, which allow for accurate measures of $K$, we may be able to maximize water distribution and use in container substrates, thereby reducing water consumption by container nurseries.

One metric used to measure plant response to modified substrates in regard to water dynamics is water use efficiency (WUE). WUE has been described in numerous ways, from intrinsic (rate of carbon assimilation: rate of transpiration) to integrated (biomass produced: total transpiration), all of which provide useful information regarding plant-water interactions (Bacon, 2004). However, these measures may not be as important for ornamental growers, as growth alone may not be the most influential factor in sales. Another metric to measure plant-water response to modified substrates is water availability, which affects crop stress, time to market, and corresponding nutrient availability. Water availability is a measure of percentage of water held by a substrate that a plant can use to sustain life. This metric may be beneficial to producers attempting to grow with reduced water. Other metrics that should be considered are drought stress indicators, many of which are measurable. Each metric has a value to researchers and when used in concert it can provide information to the water dynamics of the substrate-plant system holistically.

The goal of this research was to determine if substrates engineered to have optimal hydraulic properties could continue to produce a quality, salable Hydrangea arborescens crop grown at $\Psi$, which was previously considered unfavorable for container production. Furthermore, we wanted to determine how suboptimal $\Psi$ influences crop physiology and morphology. Finally, we wanted to determine differences in plant water availability between the substrates engineered to have increased $K$ vs. an unaltered bark substrate conventionally used in the mid-Atlantic and southeast nursery industry. We hypothesized that these engineered substrates will provide the plant with access to higher proportions of water and increase the WUE, while reducing indicators of drought stress, which are common to plants grown at low $\Psi$ in traditional bark substrate. Moreover, the readily-available commercial materials used for engineering substrates (i.e., peat and coir fibrous materials added to bark) will affect the plant-substrate water dynamics measured through subsequent plant physiology and morphology.

\section{Materials and Methods}

Substrate preparation. On 10 Mar. 2016, we acquired $\approx 1.2 \mathrm{~m}^{3}$ of aged ( $\approx 6$ months) loblolly PB ( Pinus taeda L.) passed through a $12.6-\mathrm{mm}$ screen at a commercial bark processing plant (Pacific Organics, Henderson, NC). The bark was then separated into two particle size fractions by shaking it through a 4-mm screen (W.S. Tyler, Mentor, $\mathrm{OH}$ ) rotating at about eight oscillations per second in a custom fabricated shaker (Steve's Welding, Williamston, SC) at the Substrates Processing and Research Center at North Carolina State University, Raleigh, NC. The process entailed shoveling $\approx 0.1 \mathrm{~m}^{3}$ of $\mathrm{PB}$ $(66.4 \% \pm 1.1 \%$ SE moisture content $)$ into the shaker tray to a depth of $\approx 7 \mathrm{~cm}$ and shaking for $5 \mathrm{~min}$. The bark was then separated into two separate $0.19 \mathrm{~m}^{3}$ drums; we stored the bark that passed through the 4-mm screen, termed as fine bark (FB), and bark that did not pass through the 4-mm screen. The screening process separated the bark by $\approx 50 \%$ by volume (i.e., the volume of the bark that passed through the screen was equal to that did not pass through). An additional $0.19 \mathrm{~m}^{3}$ drum was filled with $<12.6 \mathrm{~mm}$ PB termed unprocessed bark (UB). All the drums were sealed to prevent moisture loss and transported to the Virginia Tech Hampton Roads Agricultural Research and Extension Center in Virginia Beach, VA for blending, analysis, and experimentation.

Using particles that did not pass through the $4.0-\mathrm{mm}$ screen, we blended two additional substrates with $35 \%$ (by vol.) compressed Sphagnum peatmoss [bark-peat (BP); Fafard, Agawam, MA] or $35 \%$ (by vol.) coir [bark-coir (BC); FibreDust, LLC, Glastonbury, $\mathrm{CT}]$ that were previously hydrated in sealed plastic tubs for $24 \mathrm{~h}$ to equilibrate. These component amendment ratios were based on preliminary analyses to mimic static physical properties to that of the conventional bark, while keeping equal amendment ratios of the two fibrous additions (data not shown), even though $\approx 50 \%$ of the volume of the unaltered bark was removed. These two substrates were then placed into $0.19 \mathrm{~m}^{3}$ drums and sealed.

Physical properties. Measurement included minimum AS, CC, total porosity (TP), and bulk density ( $\mathrm{Db})$ via porometer analysis (Fonteno and Harden, 2010) for three replicates of each substrate using a $347 \mathrm{~cm}^{3}$ aluminum core. Particle size distributions of three replicates were measured for each substrate by shaking $100 \mathrm{~g}$ of oven dried substrate for 5 min with a Ro-Tap shaker (Rx-29; W.S. Tyler, Mentor, $\mathrm{OH}$ ) equipped with 6.30, 2.00, $0.71,0.50,0.25$, and $0.11 \mathrm{~mm}$ sieve and a pan Particles remaining on each sieve or in the pan after shaking were weighed and used to determine particle size distribution by weight.

Hydraulic properties. Saturated $K_{\mathrm{s}}$ of each substrate was measured using a KSAT device (Decagon Devices, Pullman, WA). Each substrate was filled from the top into a three-section column consisting of two $250 \mathrm{~cm}^{3}$ cores attached below and above the $250 \mathrm{~cm}^{3}$ sample core. The $250 \mathrm{~cm}^{3}$ was lifted and dropped from $5 \mathrm{~cm}$ height five times to obtain uniform $\mathrm{Db}$ within the sample core for each substrate. The packed sample core was removed by taking care not to disturb the bark at either opening before covering with a cheesecloth. Cores were then placed into a plastic tub, saturated slowly from the bottom, and left for $24 \mathrm{~h}$ to equilibrate before being affixed with a collar and an appropriate upper and lower screen (all included with the KSAT device). Samples were then placed into the KSAT device and again saturated from the base to replace any water lost during preparation. The saturated $K$ was measured three sequential times for each of the three replicates in the constant head measurement mode before being removed from the device.

Substrate water potentials $<-1.0 \mathrm{MPa}$ were measured via a dewpoint potentiameter (WP4C; Decagon Devices) following procedures described by Fields (2013). Each substrate was used to fill stainless steel sampling dishes (Decagon Devices) to completely cover the bottom surface of the dish $(\approx 0.5 \mathrm{~cm}$ depth $)$ and dried to different degrees (to ensure varying $\mathrm{MC}$ in each dish before measurement). Each dish was sealed in the dewpoint potentiameter drawer, and substrate water potential $(\Psi)$ was measured on "Precise Mode." Dishes were immediately weighed after each measurement and then dried in a forced air drying oven at $105{ }^{\circ} \mathrm{C}$ for $48 \mathrm{~h}$. This process was repeated until five measurements between -1.0 and $-4.0 \mathrm{MPa}$ were attained for each substrate, and corresponding VWCs were calculated using measured $\mathrm{Db}$.

MCCs and unsaturated $K$ curves were developed for each substrate via the evaporative method using a Hyprop (UMS, Munich, Germany) following the procedures described by Fields et al. (2016). Each substrate was packed using a column assembly as with previous analyses. Data for each substrate, including TP, $K_{\mathrm{s}}$, and values obtained via dewpoint potentiametry, were then compiled with HypropFit software (UMS). Moisture characteristic data were modeled using the Brooks and Corey (1964) model to generate predictive curves of MCCs. The measured $K(\Psi)$ data were plotted, and the MCC data based on effective saturation measured via the evaporative method were used along with the $K(\Psi)$ measurements to fit a $K(\Psi)$ model in HypropFit. This model predicted $K$ across the measured tension range and weighted the actual $K(\Psi)$ measurements to produce the strongest fit. The fit was computed (in HypropFit) with a nonlinear regression algorithm that minimized the sum of weighted squared residuals between model prediction (based on MCC measures) and measured $K(\Psi)$ data.

Low water crop production. On 5 June 2016, the previously sealed drums containing the four substrates were agitated to ensure homogenization and uniform moisture distribution for each of the four substrates. A volume of $0.13 \mathrm{~m}^{3}$ of each substrate was amended, each with $5.63 \mathrm{~kg} \cdot \mathrm{m}^{-3}$ controlled-release fertilizer 
(15.0N-3.9P-9.9K 3-mo Osmocote Plus, third generation with micronutrients, The Scotts Co. LLC, Marysville, $\mathrm{OH}$ ) and 4.15 $\mathrm{kg} \cdot \mathrm{m}^{3}$ lime $[1: 1$ crushed (Rockydale Quarries Corp., Roanoke, VA): pulverized (Old Castle Lawn \& Garden, Inc., Atlanta, GA) by weight]. Thirty-two $3.8-\mathrm{L}$ containers (C400; Nursery Supplies, Chambersburg, PA) were filled loosely to the lip with each substrate and dropped from a $5 \mathrm{~cm}$ height three times to provide a $\mathrm{Db}$ equivalent to that of the cores packed in the laboratory portions of this research. Hydrangea arborescens (L.) 'Annabelle' liners (Carlton Plants, Dayton, OR) were planted in 21 containers of each substrate. Each plant was placed in the center of the container and again dropped once from a height of $5 \mathrm{~cm}$ to complete planting. The remaining 11 containers of each substrate remained unplanted (fallow), and five of these fallow containers were immediately oven-dried to determine substrate dry weight and $\mathrm{Db}$. The 84 planted containers (four substrates $\times 21$ containers) and 24 fallow containers (four substrates $\times$ six containers) were moved into a shaded mist house, hand watered, and left in the mist house for $7 \mathrm{~d}$ to allow for root establishment.

On 13 June 2016, all planted containers were moved onto an open air nursery gravel pad and placed under daily overhead irrigation $\left(20 \mathrm{~min} \cdot \mathrm{d}^{-1}\right)$ for $21 \mathrm{~d}$ for continued establishment. On 12 July 2016, the plants were pruned to an uniform size and placed on benches in a climate-controlled greenhouse. The benches had 12 separate irrigation zones. Each zone consisted of a solenoid valve controlling 10 individual pressure compensating spray stakes (Plum color; $12.1 \mathrm{~L} \cdot \mathrm{h}^{-1}$; Netafim USA, Fresno, CA) used to water nine containers and a water collection vessel, which measured application volume and frequency. Each irrigation zone was used for a single substrate (treatment) with three separate irrigation zones (replicate) assigned to each treatment. We placed one plant and one fallow container on two randomly located lysimeters [load cells (LSP-10; Transducer Techniques, Temecula, CA) with $29.2 \mathrm{~cm}^{2}$ plates mounted on each side] in each replication connected to a data logger (CR3000 Micrologger; Campbell Scientific, Logan, UT) via a multiplexer (AM16/32B Relay Multiplexer; Campbell Scientific) that recorded the weight of the container system every $5 \mathrm{~min}$. Air temperature (T) and relative humidity (RH) at canopy height were measured every 5 min with a HMP60 probe (Vaisala, Vantaa, Finland) via the data logger. The total irrigation events for each replicate were logged and used to calculate irrigations per day, and total applied water volume was used to calculate time average application rate $\left(\mathrm{mL} \mathrm{H}_{2} \mathrm{O}\right.$ per $\left.\mathrm{h}\right)$.

One representative plant from each replicate was used for an initial baseline harvest on 14 July 2016. Data measured included leaf length (LL; from leaf tip to leaf base) of the four most apical mature leaves, leaf area (LA; LI-3100C; LI-COR Biosciences, Lincoln,
$\mathrm{NE}$ ), leaf number, and root index [RI; (rooting depth + widest rooting width + perpendicular rooting width)/3]. Roots and shoots were separated, washed clean of debris, dried at $105^{\circ} \mathrm{C}$ for $7 \mathrm{~d}$, and weighed. In addition, we measured growth index [GI; (height + widest width + perpendicular width)/3] of each plant, extracted pore water (LeBude and Bilderback, 2009) on three randomly selected plants in each replicate to determine initial electrical conductivity and $\mathrm{pH}$. One hundred fifty milliliters of liquid fertilizer solution $\left(12 \mathrm{~g} \cdot \mathrm{L}^{-1}\right.$ of soluble $20 \mathrm{~N}-8.6 \mathrm{P}-16.6 \mathrm{~K}$ fertilizer solution; JR Peters, Inc., Allentown, PA) was then applied to each container by hand to provide additional nutrition levels through the remainder of the study.

On 15 July 2016 [0 d after initiation (DAI)], automated irrigation control was initiated. A solenoid was actuated, via relays (SDM-CD16AC AC/DC Relay Controller; Campbell Scientific) when the minimum weight of the plant-container system on a lysimeter was equal to a corresponding $\Psi$ of $-300 \mathrm{hPa}$. Plants continued to receive irrigation until the substrate reached a calculated weight corresponding to a $\Psi$ of $-100 \mathrm{hPa}$. The critical weights (when irrigation was initiated and ended) of each substrate was determined using each substrate dry weight from previously collected fallow containers and substrate MCCs. A leaching pan, with riser, was placed under a random plant in each replicate to measure the volume of water leached after each irrigation. A single emitter from each zone was placed in a bottle to collect and quantify water application. The growth index was calculated about every $10 \mathrm{~d}$ (0 DAI, 11 DAI, 21 DAI, and 32 DAI).

Instantaneous water use measurements. On 17 and 32 DAI, a portable photosynthesis system (LI-6400XT; LI-COR Biosciences) with a light-emitting diode equipped gas exchange chamber was used to measure leaf gas flux including net photosynthesis $\left(P_{n}\right)$, stomatal conductance $\left(g_{\mathrm{s}}\right)$, and transpiration. Data were measured between 1100 and 1215 HR on both days with the atmospheric and environmental parameters for the measurements on 17 DAI as follows: $T=30.1{ }^{\circ} \mathrm{C} \pm$ $1.2 \mathrm{SD} ; \mathrm{RH}=46.3 \% \pm 3.0 \mathrm{sD}$; photosynthetic active radiation $(P A R)=980 \mu \mathrm{mol} \cdot \mathrm{m}^{-2} \cdot \mathrm{s}^{-1} \pm$ 494 SD and for $32 \mathrm{DAI}$ as follows: $T=29.6^{\circ} \mathrm{C}$ $\pm 0.7 \mathrm{SD} ; \mathrm{RH}=66.5 \% \pm 2.3 \mathrm{SE} ; P A R=1455$ $\mu \mathrm{mol} \cdot \mathrm{m}^{-2} \cdot \mathrm{s}^{-1} \pm 426 \mathrm{SD}$. One representative plant of each replicate was selected for measurement and clamped the leaf chamber fluorometer onto an apical mature leaf ensuring that the leaf was not contorted, and the entire area of the chamber $\left(6 \mathrm{~cm}^{2}\right)$ covered the leaf tissue. This process was done quickly $(<90 \mathrm{~s})$ to minimize any possible shadowing that may affect the system or the plant. The chamber mimicked the PAR, T, and RH of the greenhouse environment at the time of measurement. The $\mathrm{CO}_{2}$ concentration within the chamber was set to 404.8 and $400.5 \mu \mathrm{mol} \cdot \mathrm{mol}^{-1} \pm 0.2 \mathrm{SE}$ for 17 and $32 \mathrm{DAI}$, respectively.

In addition, a pressure chamber (Model 600; PMS Instrument Co., Albany, OR) was used to measure the water potential of a severed apical stem consisting of three nodes $(\approx 10 \mathrm{~cm})$ at $32 \mathrm{DAI}$ immediately following gas exchange measurements. Once severed, the stem was immediately fit into a rubber stopper with clay to create an airtight seal. The stem was then sealed in the pressure chamber with the severed surface exposed to the atmosphere. We incrementally increased pressure of the chamber using compressed nitrogen gas until liquid was first observed exiting the severed stem surface. The entire process was conducted in $<120 \mathrm{~s}$ to prevent tissue desiccation.

Harvest. On 32 DAI, four plants in each replicate were harvested, including the plant used for instantaneous water status measurements and the plant used for irrigation control. The growth index was measured on all four plants harvested. The plant on the lysimeter of each replication had all leaves removed, LA measured, and total leaf number counted. The leaf length, as an indicator or plant water status throughout the experiment as impacted by cell elongation (Pallardy, 2008), was measured on (base to tip, excluding petiole) the four most apical mature leaves of all harvested plants. Compactness was calculated as the ratio of shoot dry mass to shoot height (van Iersel and Nemali, 2004). Shoots (above substrate plant material) were severed at the surface of the substrate, and roots were washed free of substrate. All plant tissue was dried in a convection oven at $58{ }^{\circ} \mathrm{C}$ for $7 \mathrm{~d}$.

Plant water availability. Beginning 32 DAI, irrigation was turned off, spray stakes removed, and two plants and a fallow container in each replication were hand watered to effective CC. One plant and one fallow container were placed on a lysimeter in each irrigation zone and water loss through evaporation and/or transpiration was recorded until all plants were completely wilted for $>2 \mathrm{~d}$. The VWC determined to be the transition between evapotranspiration (ET) and evaporation was then converted to water potential using the MCC data for each substrate. Daily reductions in substrate VWC were plotted against the VWC and verified by fitting volumetric water content data to a model which calculated the point where the transition from nonlinear (during ET) to linear (evaporation) occurred (data not shown). Using these data plots, the intersection where the data become asymptotic was used to determine when water loss switched from primarily transpiration to primarily evaporation.

Data analysis. Data presented in tables with associated statistics were analyzed in JMP Pro (12.0.1; SAS Institute, Inc., Cary, NC) using the Dunnett's test $(\alpha=0.05)$ to compare the engineered substrates to the UB (control). We separated the means of the three engineered substrates using the Tukey's Honestly Significant Difference (HSD; $\alpha=$ $0.05)$. The $\mathrm{MCC}$ and $K(\Psi)$ model were computed (in HypropFit) using Brooks and Corey (1964) with a nonlinear regression algorithm that minimized the sum of weighted squared residuals between model 
prediction (based on MCC measures) and measured $K(\Psi)$ data for the best fit. Root mean square error was computed to determine how strong the $K(\Psi)$ model fit the measured $K(\Psi)$ data.

Data in tables without accompanying statistics were computed or modeled from raw data. Correlation data were calculated using Pearson product-moment correlation coefficient in JMP Pro (12.0.1). Nonlinear regression for determining transition between linear and nonlinear data in the water availability study was calculated using PROC NLIN in SAS (9.3; SAS Institute).

\section{Results and Discussion}

Physical properties. The physical properties of FB and UB were within ranges recommended by BMPs (Bilderback et al., 2013). Minimum AS in BC and BP was outside of the BMP range (Table 1). TP varied with $\mathrm{FB}$ and $\mathrm{BP}$ being an average of $6.6 \%$ (by vol.) greater than UB and $3.3 \%$ less than BC. The BC had the largest TP, indicating increased porosity when coarse bark is equally amended with coir vs. peat. Minimum air space between BP, BC, and UB ranged from $30.7 \%$ to $40.6 \%$ (by vol.; Table 1). The UB was near the upper limit of recommended AS. The screening process removed $50 \%$ of the volume from the coarse bark, which was replaced by only $35 \%$ of the fibrous materials, and therefore, the BP and $\mathrm{BC}$ had a larger percentage of coarse bark particles. PB screened to $<4 \mathrm{~mm}$ (FB) had an $\approx 18 \%$ shift in AS (18.2\% by vol.) and CC (64.1\% by vol.) increasing substrate water storage $\approx 650 \mathrm{~mL}$ compared with the other substrates in the study, when scaled up to a 3.9-L container.

Bulk density of engineered substrates ( $\mathrm{FB}, \mathrm{BP}$, and $\mathrm{BC}$ ) differed from conventional $\mathrm{UB}$, with peat or coir amended bark being $0.06 \mathrm{~g} \cdot \mathrm{cm}^{-3}$ less and FB being $0.05 \mathrm{~g} \cdot \mathrm{cm}^{-3}$ greater (Table 1). This result demonstrates the dominance of the overall amount of PB in the container as seen in part by examining the particle texture class. FB had about twice the amount of fine $(<0.7 \mathrm{~mm})$ particles compared with the other substrates. The particle textures of UB increased by fine < medium $<$ coarse particles, unlike the fiber amended substrates which had the largest percentage of coarse particles and lowest percentage of medium particles (Table 1). The removal of bark fines and subsequent replacement with fibrous materials (with lower $\mathrm{Db}$ than bark) resulted in reduced overall $\mathrm{Db}$ similar to previous observations by Pokorny et al. (1986). The Db of FB was greater than all other substrates resulting from reduced AS incurred from removing coarse particles. Bulk density is an important factor in developing soilless substrates, as lighter substrates are less costly to transport (Knox and Chappell, 2014). As a result, we believe that good growth and crop water dynamics in $\mathrm{BP}$ and $\mathrm{BC}$ may be more advantageous than in FB.

Hydraulic properties. The $K$ models, calculated from the MCC data and weighted with measured values, provided adequate fit for data against the measured $K$ data within the $\Psi$ range of 0 to $-300 \mathrm{hPa}$ (RMSE $=2.7$, $0.3,3.6$, and $3.3 \log _{10} \mathrm{~cm} \cdot \mathrm{d}^{-1}$ for UB, FB, BP, and $\mathrm{BC}$, respectively). Additional comparisons were made using $K$ at $\Psi=-200 \mathrm{hPa}$ $\left(K_{-200}\right)$ and the median $K$ value. The $K$ models revealed that the $K_{-200}$ from the greatest to the least was $\mathrm{FB}, \mathrm{BC}, \mathrm{BP}$, and $\mathrm{UB}$. The resulting increased container capacity and fine particles from FB resulted in increased $K_{-200}$ facilitating water movement within the substrate at lower $\theta$ (Table 1). We further plotted the models based on our substrate $K(\Psi)$ measurements over the crop production range in this research $[K \mathrm{p}(\Psi$ between -100 and $-300 \mathrm{hPa}$ ); Fig. 1] because a primary objective of the substrate engineering process was to increase $K$ when compared with UB. Across $K(\Psi)$, the FB models had increased $K \mathrm{p}$ by about an order of magnitude.

We were unable to detect any differences in $K_{\mathrm{s}}$ between UB and BP or FB. However, $K_{\mathrm{s}}$ of BC was more than twice the value of any other substrate (Table 1 ). In addition, we successfully increased $K \mathrm{p}$ in all three engineered substrates (Fig. 1) compared with UB. We wanted to know if $K_{\mathrm{s}}$ was correlated with $K \mathrm{p}$ and as a result calculated the value of $K_{-200}$ from the models represented in Table 1 . We found little correlation $(r=0.04$, $P=0.8985)$ between $K_{-200}$ and $K_{\mathrm{s}}$. This leads us to believe that while $K_{\mathrm{s}}$ is easily measured, knowing $K_{\mathrm{s}}$ may not inform practitioners about $K \mathrm{p}$ at least at lower $\Psi$. However, this hypothesis will need to be tested when using other production $\Psi$, as often crops are produced at a less negative $\Psi$, closer to saturation, than in this study.

The MCCs of substrates with fibrous additions (BP, BC) fit using the Brooks and Corey model (1964; Fig. 2C and D) exhibit pronounced bimodal curvature, which is not observed in FB (Fig. 2B). We observe slight bimodal curvature in the UB (Fig. 2A). This is a result of increased tensions that must be applied to vacate the water from the associated pores. Therefore, the MCC shape leads us to theorize that there is a noncontinuous pore size distribution likely because of the variation in particle size between the largest fibrous particles and the smallest plate-like (bark) particles. These shifts occur at $\Psi$ between -25 and $-75 \mathrm{hPa}$ in both fiber containing substrates at which point water is considered to be readily available to plants (Pustjarvi and Robertson, 1975). This indicates that these substrates would retain more water in these ranges as the pore distribution may prevent water from readily vacating pores.

The Brooks and Corey model parameters were further used to provide estimations of the largest pore diameter and pore uniformity. The models provided a strong fit to the data for all substrates (Table 2). The air entry pressure, often considered to be indicative of the largest pore diameter, can be transformed using the Kelvin equation (Hillel, 1998) to calculate the pore diameters of the largest free void space across substrates as follows: $\mathrm{FB}=0.08 \mathrm{~cm}<\mathrm{UB}=0.14 \mathrm{~cm}<\mathrm{BC}=0.29$ $\mathrm{cm}<\mathrm{BP}=0.51 \mathrm{~cm}$. The substrate with the greatest $\alpha$ and corresponding smallest entry pore was FB because of the increased fine texture particles compared with UB. We observed that the replacement of FB particles in $\mathrm{BP}$ and $\mathrm{BC}$ with fibers allowed larger pores to form within the substrate, when compared with UB. We hypothesize this is as a result of the physical form of the fibers themselves as coir tends to have longer fibers when compared with peat (Abad et al., 2005). While measures of air entry is informative for some metrics such as gas diffusivity (Caron et al., $2005)$, it was weakly correlated with $K_{\mathrm{s}}(r=$ $-0.35, P=0.6502)$ and with $K_{-200}(r=-0.71$,

Table 1. Hydrophysical properties for four bark substrates maintained at low substrate water potentials. Substrates include a control (UB), bark particles $<4$ mm (FB), bark $>4 \mathrm{~mm}$ with $35 \%$ by vol. Sphagnum peatmoss (BP), and bark $>4 \mathrm{~mm}$ with $35 \%$ coir (BC).

\begin{tabular}{|c|c|c|c|c|c|c|c|c|c|}
\hline \multirow[b]{3}{*}{ Substrate } & \multicolumn{4}{|c|}{ Static physical properties ${ }^{z}$} & \multicolumn{2}{|c|}{ Hydraulic conductivity } & \multirow{2}{*}{\multicolumn{3}{|c|}{ Particle texture classes ${ }^{\mathrm{y}}$}} \\
\hline & Minimum & Container & Total & Bulk & & Water & & & \\
\hline & $\begin{array}{c}\text { air space } \\
\text { (percent vol.) }\end{array}$ & $\begin{array}{c}\text { capacity } \\
\text { (percent vol.) }\end{array}$ & $\begin{array}{c}\text { porosity } \\
\text { (percent vol.) }\end{array}$ & $\begin{array}{l}\text { density } \\
\left(\mathrm{g} \cdot \mathrm{cm}^{-3}\right)\end{array}$ & $\begin{array}{c}\text { Saturated } \\
\left(\mathrm{cm} \cdot \mathrm{d}^{-1}\right)\end{array}$ & $\begin{array}{c}\text { potential }=-200 \mathrm{hPa} \\
\left(\log _{10} \mathrm{~cm} \cdot \mathrm{d}^{-1}\right)\end{array}$ & $\begin{array}{l}\text { Coarse } \\
\left(\mathrm{g} \cdot \mathrm{g}^{-1}\right)\end{array}$ & $\begin{array}{c}\text { Med } \\
\left(\mathrm{g} \cdot \mathrm{g}^{-1}\right)\end{array}$ & $\begin{array}{l}\text { Fine } \\
\left(\mathrm{g} \cdot \mathrm{g}^{-1}\right)\end{array}$ \\
\hline$\overline{\text { Unprocessed (UB) }}$ & 30.7 & 45.2 & 75.9 & 0.19 & 8,128 & -6.77 & 0.52 & 0.29 & 0.18 \\
\hline Fines $(\mathrm{FB})$ & $18.2 \mathrm{a}^{\mathrm{x} * \mathrm{w}}$ & $64.1 \mathrm{~b}^{*}$ & $82.3 b^{*}$ & $0.24 \mathrm{a}^{*}$ & $8,530 \mathrm{~b}$ & -3.70 & $0.18 \mathrm{~b}^{*}$ & $0.50 \mathrm{a}^{*}$ & $0.32 \mathrm{a}^{*}$ \\
\hline Bark-peat (BP) & $37.0 \mathrm{~b}^{*}$ & $45.6 \mathrm{a}$ & $82.6 b^{*}$ & $0.13 \mathrm{~b}^{*}$ & $7,731 \mathrm{~b}$ & -6.25 & $0.71 \mathrm{a}^{*}$ & $0.16 b^{*}$ & $0.13 \mathrm{~b}$ \\
\hline Bark-coir (BC) & $40.6 b^{*}$ & $45.1 \mathrm{a}$ & $85.7 \mathrm{a}^{*}$ & $0.13 \mathrm{~b}^{*}$ & $19,227 \mathrm{a}^{*}$ & -5.57 & $0.71 \mathrm{a}^{*}$ & $0.18 \mathrm{~b}^{*}$ & $0.11 \mathrm{~b}$ \\
\hline Pval $^{\mathrm{v}}$ & $<0.0001$ & $<0.0001$ & 0.0004 & $<0.0001$ & 0.0102 & NA & $<0.0001$ & $<0.0001$ & 0.0015 \\
\hline
\end{tabular}

${ }^{\mathrm{z}}$ Measured via porometer analysis. Total porosity $=$ minimum air space + maximum water holding (container capacity)

${ }^{\mathrm{y}}$ Percent of particle dry weight occupying coarse $>2.0 \mathrm{~mm}, 2.0>$ medium $>0.7$, and fine $<0.7 \mathrm{~mm}$.

${ }^{\mathrm{x}}$ Letters denote detected differences among means of three engineered substrates (FB, BP, and BC) using the Tukey's HSD ( $\left.\alpha=0.05\right)$.

${ }^{\mathrm{w}}$ Asterisk denotes detected differences between treatment and UB (control).

${ }^{\mathrm{v}}$ Measures of overall treatment effects using analysis of variance. 
0.2904). This was unexpected as we would believe that BP, with the largest pore, would have the highest $K_{\mathrm{s}}$; however, the shape and connectivity of pores can determine if pores are "accessible," the ease that water and air can enter and exit pores (Hunt et al., 2013), which directly influences $K_{\mathrm{s}}$. We can also interpret pore size distribution index $(\lambda)$, in which a greater value indicates greater pore size uniformity; however, $\lambda$ was weakly correlated with $K_{-200}(r=0.27, P=0.7291)$ as well as with $K_{\mathrm{s}}(r=0.32, P=0.6773)$ across

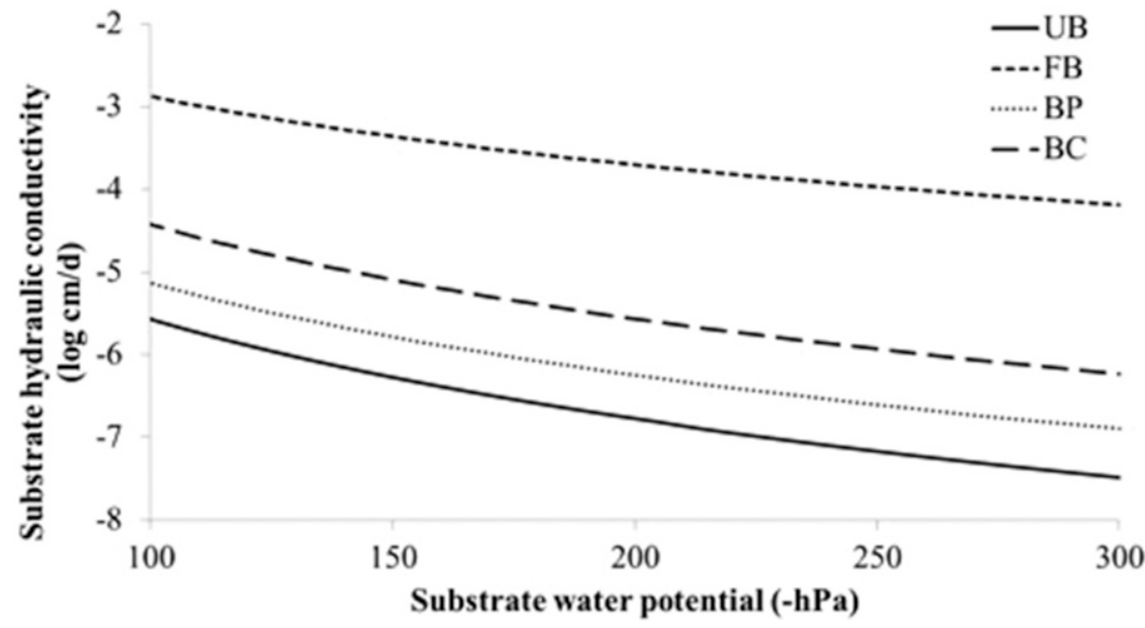

Fig. 1. Hydraulic conductivity models for substrate water potential between -100 and $-300 \mathrm{hPa}$, based on data from evaporative moisture tension and hydraulic conductivity measures of four experimental bark-based substrates. Substrates include a control (unprocessed bark, UB), bark particles $<4 \mathrm{~mm}$ (fine bark, FB), bark $>4 \mathrm{~mm}$ with $35 \%$ by vol. Sphagnum peatmoss (bark-peat, BP), and bark $>4 \mathrm{~mm}$ with $35 \%$ by vol. coir (bark-coir, BC)

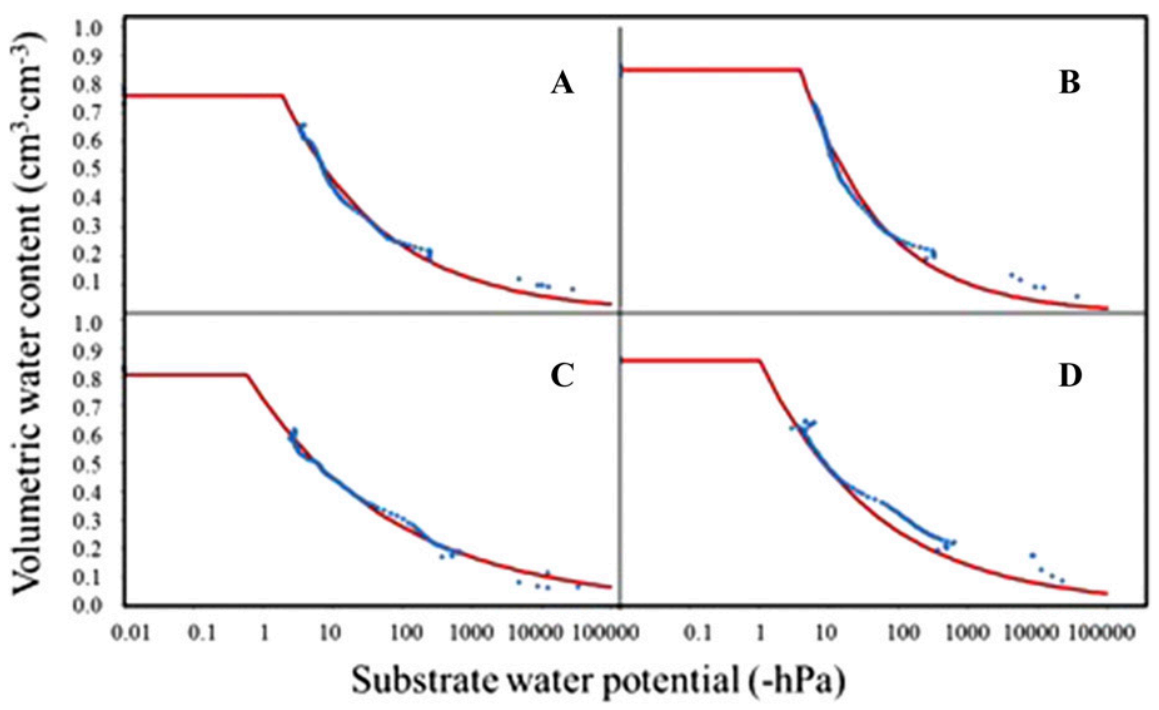

Fig. 2. Moisture characteristic data (points) fit to a Brooks and Corey (1964) model (line) for four experimental bark-based substrates. Data measured via evaporative method, porometer, and dewpoint potentiametry. Substrates include a control unprocessed bark (A), bark particles $<4 \mathrm{~mm}($ B), bark $>$ $4 \mathrm{~mm}$ with $35 \%$ by vol. Sphagnum peatmoss (C), and bark $>4 \mathrm{~mm}$ with $35 \%$ by vol. coir (D). substrates. Pore size distribution index was shown previously to be correlated with $K$ for $\Psi$ between -50 and $-100 \mathrm{hPa}$ (Fields, 2017).

We can also use the MCC models to predict the VWC of the substrates at various $\Psi$. For instance, $\Psi=1.5 \mathrm{MPa}$ have been used by soil scientists and engineers to provide estimations of unavailable water (UW) for agricultural crops. Using the models, we predict the VWC at $-1.5 \mathrm{MPa}$ for $\mathrm{BP}$ $(9.65 \%)>\mathrm{BC}(7.06 \%)>\mathrm{UB}(5.44 \%)>\mathrm{FB}$ $(3.73 \%)$. These predictions correspond with previous research that fibrous materials will retain larger volumes of water at low tensions than bark (Fields et al., 2017). Furthermore, the increased $K \mathrm{p}$ of the FB leads us to believe that because water moves more easily at lower tensions, less water will be retained at $\Psi$ near $-1.5 \mathrm{MPa}$, which is confirmed with the correlation between $K \mathrm{p}$ and UW $(r=-0.60, P=0.4646)$.

Initial baseline harvest. We were unable to detect any differences among the treatments for GI $(P=0.0806)$, LA $(P=0.2243)$, compactness $(P=0.6728)$, rooting depth $(P=$ $0.3150)$, shoot dry weight $(P=0.2170)$, and root dry weight $(P=0.1609)$ at the initiation of the experiment (i.e., start of low water irrigation after plant establishment). There were detectable differences among treatments in $\mathrm{R}: \mathrm{S}(P=0.0351)$ and $\mathrm{LL}(P=$ $0.0228)$. The Tukey's HSD detected that BP had a higher R:S than UB (5.34 to 3.06, respectively) and that $\mathrm{BC}$ had greater LL than FB (99.2 to $74.2 \mathrm{~mm}$, respectively). Aside from these two anomalies, which were likely a result of the improved rooting of liners in the fibrous materials, no other differences were detected between plants at the initiation of the study. No treatment differences were detected for EC $(P=0.4947)$; however, we did observe a difference in $\mathrm{pH}(P=0.0003)$ with the BP having $\approx 1.2$ lower $\mathrm{pH}$ than the rest of the treatments (5.5 as opposed to

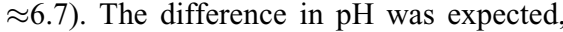
as the peat reduces the substrate $\mathrm{pH}$ more than bark (Chong et al., 1994) or coir (Abad et al., 2002) because of the inherent lower $\mathrm{pH}$ in peat. This should not have impacted crop growth because $H$. arborescens is known to be $\mathrm{pH}$ insensitive (Dirr, 2009) and all four values fall within or just above the suggested optimal $\mathrm{pH}$ range of 5.5-6.5 (Halcomb and Reed, 2012).

Low water crop production. Throughout the experiment, the difference in GI $(\Delta \mathrm{GI}=$ culmination GI - initiation GI) indicates plant growth in $\mathrm{FB}$ and $\mathrm{BC}$ accelerated after

Table 2. Model parameters and measures of fit for moisture characteristic data fit to a Brooks and Corey model (1964) for four bark substrates. Substrates include a control (UB), bark particles $<4 \mathrm{~mm}$ (FB), bark $>4 \mathrm{~mm}$ with $35 \%$ by vol. Sphagnum peatmoss (BP), and bark $>4 \mathrm{~mm}$ with $35 \%$ coconut coir (BC).

\begin{tabular}{lccccc}
\hline & \multicolumn{3}{c}{ Model parameters } & \multicolumn{2}{c}{ Measures of fit } \\
\cline { 2 - 5 } Substrate & $\begin{array}{c}\text { Saturation water } \\
\text { content } \theta \mathrm{s}\left(\mathrm{cm}^{3} \cdot \mathrm{cm}^{-3}\right)\end{array}$ & $\begin{array}{c}\text { Residual water } \\
\text { content } \theta \mathrm{r}\left(\mathrm{cm}^{3} \cdot \mathrm{cm}^{-3}\right)\end{array}$ & $\begin{array}{c}\text { Air entry point } \\
\mathrm{h}_{\mathrm{b}}\left(1 \cdot \mathrm{cm}^{-1}\right)\end{array}$ & $\begin{array}{c}\text { Pore size dist. } \\
\text { Index }(\lambda)\end{array}$ & $\begin{array}{c}\text { RMSEz } \\
\left(\mathrm{cm}^{3} \cdot \mathrm{cm}^{-3}\right)\end{array}$ \\
\hline unprocessed (UB) & 0.76 & 0.09 & 2.1555 & 0.3905 & 0.99 \\
Fines (FB) & 0.85 & $7.4 \times 10^{-6}$ & 3.7464 & 0.3771 & 0.98 \\
Bark-peat (BP) & 0.81 & $5.1 \times 10^{-6}$ & 0.5813 & 0.2092 & 0.99 \\
Bark-coir (BC) & 0.86 & 0.06 & 1.0193 & 0.2602 & 0.98 \\
\hline
\end{tabular}

${ }^{\mathrm{z}}$ Root mean square error of predicted (model) data vs. observed (measured) data points. 
11 DAI, whereas plants in BP and UB grew slower. Hereon, $\Delta$ before a metric denotes the difference between values at 0 and 32 DAI. After 21 DAI, plants began to grow faster in BP than those produced in UB (Fig. 3). Substrate $K_{-200}$ decreases from $\log _{10}-3.70 \mathrm{~cm} \cdot \mathrm{d}^{-1}$ (BC) to $\log _{10}-6.77 \mathrm{~cm} \cdot \mathrm{d}^{-1}$ (UB), in the same sequence as observed in final GI (data not shown). The $\Delta$ GI was correlated with $K_{200}(r=$ $0.69, P=0.0119)$ which further provides evidence that $K$ p impacts growth for container crops particularly when grown at substrate $\Psi$ between -100 and $-300 \mathrm{hPa}$. However, the correlation between $\Delta \mathrm{GI}$ and $K_{\mathrm{s}}$ was weak ( $r=0.15, P=0.6326)$; therefore, we

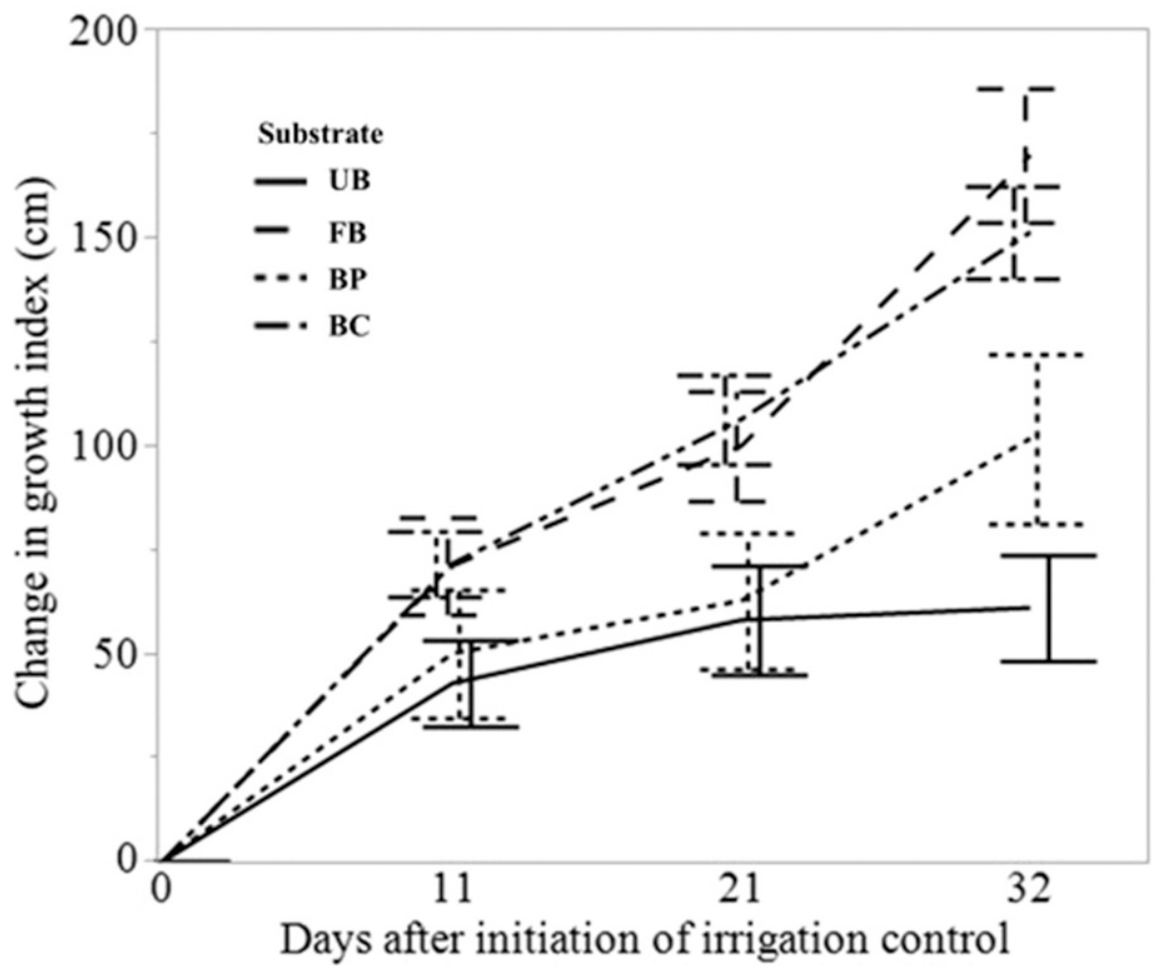

Fig. 3. Growth index of containerized plants grown in four experimental substrates at substrate water potentials between -100 and $-300 \mathrm{hPa}$ for $32 \mathrm{~d}$. Plant growth index was normalized to at the initiation of the research to demonstrate changes over the experimental production period. Substrates include a control (unprocessed bark, UB), bark particles $<4 \mathrm{~mm}$ (fine bark, FB), bark $>4 \mathrm{~mm}$ with $35 \%$ by vol. Sphagnum peatmoss (bark-peat, BP), and bark $>4 \mathrm{~mm}$ with $35 \%$ by vol. coir (bark-coir, BC). conclude that $K \mathrm{p}$ is more informative in container production as opposed to $K_{\mathrm{s}}$ which may be informative on water application rate and efficiency because of localized pore saturation during initial irrigation. Crop $\Delta \mathrm{GI}$ in $\mathrm{FB}$ and $\mathrm{BC}$ was greater than that of $\mathrm{UB}$ $(P=0.0287$; Table 3$)$. With the substrate water potential below optimal conditions, the UB (which aligns with the SNA BMP's for static physical properties) was unable to supply the plant with sufficient water to support equal growth as compared with the other treatments with increased $K$. This inability to access water in UB is not believed to be a result of direct root contact as there were no differences in final rooting depth $(P=0.8225)$ nor R:S $(P=0.4048$; data not shown).

There were no differences between treatments in $\Delta$ rooting depth, as nearly all plants had roots which reached the bottom of the container (Table 3). We observed increased $\Delta \mathrm{LL}$ in FB plants when compared with those in UB and increased difference in $\triangle \mathrm{LA}$ in $\mathrm{BC}$ plants compared with UB plants (Table 3 ). We also observed overall treatment effects in $\Delta \mathrm{LA}(P=0.0313)$ and $\Delta \mathrm{LL}(P=0.0460)$ which indicate differences in water stress exhibited by the plants due to the substrate. LA and reduced LL have both shown to have a direct relationship with moisture content and subsequent drought stress (van Iersel and Nemali, 2004) or as a metric of drought stress indicated by leaf expansion (McCree, 1986), respectively. The correlation of $\Delta \mathrm{LL}$ with $K_{200}(r=0.68, P=0.0142)$ illustrates that $K \mathrm{p}$ can be potentially used to estimate any potential effects of water stress perceived by plants. There were also treatment differences in $\triangle \mathrm{R}: \mathrm{S}(P=0.0292)$, and BP plants had more negative $\Delta \mathrm{R}: \mathrm{S}$ than UB plants (Table 3); however, this may be an artifact of the initial rooting differences. The plants grown in $\mathrm{BC}$ had increased $\Delta$ compactness than those in UB $(P=0.0782$; Table 3$)$. The increased compactness indicates more mass per canopy volume and has been linked to increased substrate moisture (Bayer et al., 2013) and reduced drought stress (van Iersel and Nemali, 2004). Moreover, we observed that plants in $\mathrm{BC}$ had larger $\Delta$ compactness than plants in BP, which points to the differences in the fiber amendments. We were unable to find any final morphological metrics with strong correlations with $K_{\mathrm{s}}(r<$ $|0.4502|$ in all cases). In fact, all final physiological metrics were more strongly correlated with $K_{-200}$ than $K_{\mathrm{s}}$.

On 32 DAI, the treatment effects were most pronounced across all treatments $(P<$ $0.0001)$, with plants grown in $\mathrm{BC}(451.0 \mathrm{~cm})$ having the greatest growth in the experiment, FB (426.5) and BP (376.9) were similar, and UB (307.7) was the lowest. Plant maximum growth may have occurred in $\mathrm{BC}$ vs. $\mathrm{FB}$

Table 3. Differences in plant physiological and morphological measures from initiation to culmination of low substrate water potential production (i.e., value at 32 DAI - 0 DAI). Root vigor rating is a subjective measure only of the final rooting determined by an author at harvest (32 DAI). Substrates include a control (UB), bark particles $<4 \mathrm{~mm}$ (FB), bark $>4 \mathrm{~mm}$ with $35 \%$ by vol. Sphagnum peatmoss (BP), and bark $>4 \mathrm{~mm}$ with $35 \%$ coconut coir (BC).

\begin{tabular}{|c|c|c|c|c|c|c|c|}
\hline Substrate & $\begin{array}{c}\text { Leaf } \\
\text { length }^{\mathrm{z}}(\mathrm{mm})\end{array}$ & $\begin{array}{c}\text { Leaf } \\
\text { area }^{y}\left(\mathrm{~cm}^{2}\right)\end{array}$ & $\begin{array}{c}\text { Root } \\
\text { depth }^{\mathrm{x}}(\mathrm{mm})\end{array}$ & $\begin{array}{l}\text { Root: } \\
\text { Shoot }^{\mathrm{w}}\end{array}$ & $\begin{array}{c}\text { Compactness }{ }^{\mathrm{V}} \\
\left(\mathrm{g} \cdot \mathrm{cm}^{-1}\right)\end{array}$ & $\begin{array}{c}\text { Growth } \\
\text { index }^{\mathrm{u}}(\mathrm{cm})\end{array}$ & $\begin{array}{c}\text { Root } \\
\text { vigor rating }\end{array}$ \\
\hline Fines $(\mathrm{FB})$ & $48.6^{* t}$ & 1983.2 & 26.67 & -3.458 & $0.2397 \mathrm{ab}^{\mathrm{s}}$ & $169.5^{*}$ & $2.8^{*}$ \\
\hline Bark-peat (BP) & 29.5 & 1454.4 & 14.17 & $-5.042 *$ & $0.2016 \mathrm{~b}$ & 101.4 & 2.2 \\
\hline $\mathrm{Pval}^{\mathrm{r}}$ & 0.0460 & 0.0313 & 0.4965 & 0.0292 & 0.0782 & 0.0162 & 0.0225 \\
\hline
\end{tabular}

${ }^{\mathrm{z}}$ Distance between the leaf tip and base (excluding petiole).

${ }^{\mathrm{y}}$ Total area of leaves measured with a Leaf Area Meter (LI-3300c; LI-COR Biosciences).

${ }^{\mathrm{x}}$ Deepest depth in container explored by the root system.

${ }^{\text {w }}$ Dry mass of root system $\div$ dry mass of shoot system.

${ }^{\mathrm{v}}$ Shoot dry mass $\div$ shoot height.

${ }^{\mathrm{u}}$ Canopy volume, calculated as [(height + widest width + perpendicular width $) \div 3$ ]

${ }^{\mathrm{t}}$ Asterisk denotes detected differences between treatment and UB (control).

${ }^{\text {s}}$ Letters denote detected differences among means of three engineered substrates (FB, BP, and BC) using the Tukey's HSD ( $\left.\alpha=0.05\right)$

${ }^{\mathrm{r}}$ Measures of overall treatment effects using analysis of variance.

$\mathrm{DAI}=$ day after initiation 
because of superior air exchange throughout establishment, acclimation, and experimentation. Plants grown in UB had the lowest final LA $(P=0.0287)$ and $\operatorname{LL}(P=<0.0001)$, as well as the lowest compactness $(P=$ 0.0396 ) at the end of the study. As a result, the engineered substrates produced morphologically superior crops compared with the UB control (Fig. 4). Furthermore, the plants in $\mathrm{BC}$ had the greatest compactness, LA, and the plants in FB had the greatest LL. The plants produced in UB exhibited signs of drought stress in nearly every measured metric. We hypothesize that this is a result of increased $K \mathrm{p}$ in $\mathrm{FB}, \mathrm{BP}$, and $\mathrm{BC}$ allowing water to be attained when needed but not restricting the air space necessary for healthy growth. Also, the plants in BC established more rapidly after transplant (personal observation) which may have been due to the added airspace.

Plants in all treatments received little water throughout the production cycle $(<6.7$ L per plant; Table 4). Plants in FB and BC used $\approx 3 \mathrm{~L}$ more water than UB $(2.8 \mathrm{~L})$. This is a result of ET being influenced by treatment $(P=0.0188$; Table 4$)$. Irrigation systems driven by $\Psi$ have been shown to reduce water application (Scheiber and Beeson,

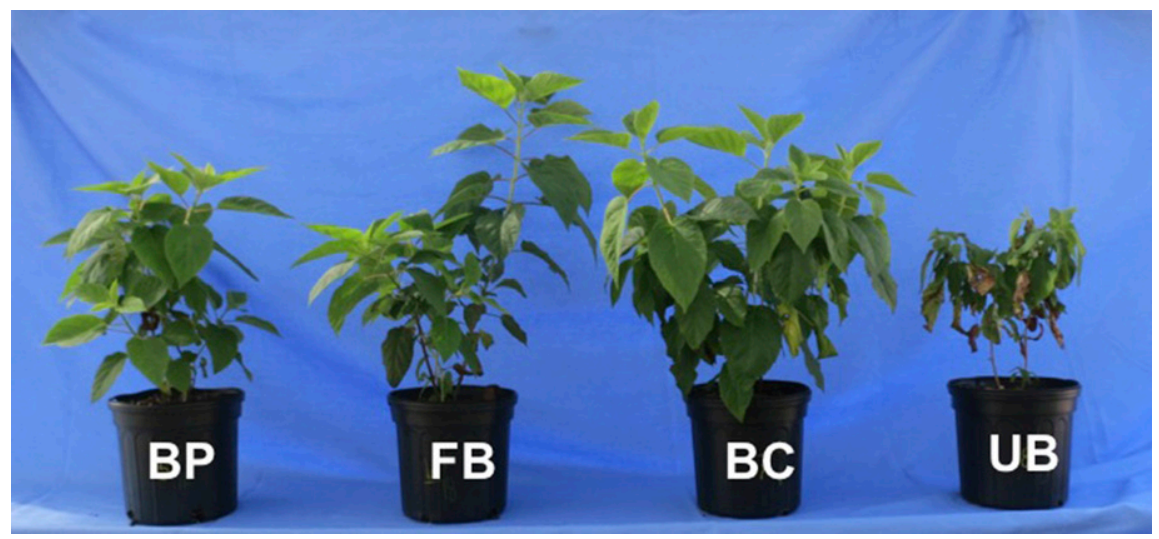

Fig. 4. A digital image of a representative plant from each of the four experimental substrate treatments collected $32 \mathrm{~d}$ after initiation of the low substrate water potential irrigation management. Substrates include a control (unprocessed bark, UB), bark particles $<4 \mathrm{~mm}$ (fine bark, FB), bark $>4 \mathrm{~mm}$ with $35 \%$ by vol. Sphagnum peatmoss (bark-peat, BP), and bark $>4 \mathrm{~mm}$ with $35 \%$ by vol. coir (bark-coir, BC). these plants to readily draw water from the substrate at production $\Psi$ between -100 and $-300 \mathrm{hPa}(\Psi \mathrm{p})$, thus increasing total irrigations over production. Conversely, there were no differences in irrigation frequency among the treatments (Table 4).

Net photosynthesis, measured 17 DAI, differed between crops grown in the FB and UB $(P=0.0812)$ using the Dunnett's test (Table 5). There were no other differences among the three engineered treatments in $P_{\mathrm{n}}$, $g_{\mathrm{s}}$, and transpiration. Still correlations between $K_{200}$ and $P_{\mathrm{n}}, g_{\mathrm{s}}$, and transpiration existed $(r=0.67,0.61$, and 0.66 , respectively, $P=0.0179,0.0340$, and 0.0205 , respectively), further indicating the influence of $K \mathrm{p}$ on crop growth when $\Psi$ remained suboptimal. At 32 DAI, instantaneous gas exchange measurements of crops grown in UB and FB differed (Table 5 ). In addition, $g_{\mathrm{s}}$ and transpiration were more strongly correlated with $K_{200}$ on 17 DAI $(r=0.71$ and 0.74 , respectively; $P=0.0093$ and 0.0058 , respectively), with $P_{\mathrm{n}}$ correlation nearly identical ( $r=0.65, P=0.0181$ ), alluding to the increasing importance of $K \mathrm{p}$ as the crop grows and requires more resources. The difference in gas exchange between 17 and 32 DAI is likely an artifact of increased plant vigor, as increased LA indicates increased transpiration (Vertessy et al., 1995). Stem water potential measures on $32 \mathrm{DAI}$ were not influenced by treatment $(P=0.6043)$, nor was there a strong correlation with $K_{200}$ (Table 5). Conversely, stem water potential correlated with $P_{\mathrm{n}}, g_{\mathrm{s}}$, and transpiration on 32 DAI $(r$ between 0.64 and 0.67 for all three metrics). These instantaneous measures should be used as relative measures to compare treatments and not make assumptions of total crop performance as they are only indicative of the plants at a single point in time. Plants in the FB treatment had the largest measured $P_{\mathrm{n}}$, $g_{\mathrm{s}}$, and transpiration of all the treatments at 32 DAI. Instantaneous WUE $\left(P_{\mathrm{n}} \div\right.$ transpiration) values for UB (17 DAI 3.55, 32 DAI 2.69), FB (17 DAI 2.89, 32 DAI 2.67), BP (17 DAI 3.56, 32 DAI 3.05), and BC (17 DAI $3.76,32$ DAI 2.01) indicates that plants in all treatments were using water more efficiently on 17 DAI than $32 \mathrm{DAI}$, which is

Table 4. Irrigation and water use efficiency (WUE) metrics for $32 \mathrm{~d}$ of containerized plant production for four substrates held at substrate water potentials between -100 and $-300 \mathrm{hPa}$. Plants were irrigated with pressure compensating spray stakes based on lysimeter readings. Substrates include a control (UB), bark particles $<4 \mathrm{~mm}$ (FB), bark $>4 \mathrm{~mm}$ with $35 \%$ by vol. Sphagnum peatmoss (BP), and bark $>4 \mathrm{~mm}$ with $35 \%$ coir (BC).

\begin{tabular}{|c|c|c|c|c|c|c|}
\hline Substrate & $\begin{array}{c}\text { Evapo- } \\
\text { transpiration }^{\mathrm{z}}(\mathrm{L})\end{array}$ & $\begin{array}{l}\text { Leaching } \\
\text { fraction } \\
\left(\mathrm{cm}^{3} \cdot \mathrm{cm}^{-3}\right)\end{array}$ & $\begin{array}{l}\text { Increase in } \\
\text { plant dry } \\
\operatorname{mass}^{\mathrm{x}}(\mathrm{g})\end{array}$ & $\begin{array}{c}\text { Irrigation } \\
\text { frequency } \\
\text { (irrigations/d) }\end{array}$ & $\begin{array}{c}\text { Time avg } \\
\text { application } \\
\operatorname{rate}^{\mathrm{w}}\left(\mathrm{cm}^{3} \cdot \mathrm{h}^{-1}\right)\end{array}$ & $\begin{array}{c}\mathrm{WUE}^{\mathrm{v}} \\
\left(\mathrm{g}^{-1} \cdot \mathrm{cm}^{-3}\right)\end{array}$ \\
\hline Unprocessed (UB) & 2.8 & 0.05 & 15.3 & 0.69 & 3.87 & 183.0 \\
\hline Fines $(\mathrm{FB})$ & $5.3 * u$ & 0.01 & $23.7 \mathrm{~b}^{\mathrm{t} *}$ & 0.71 & $6.92 *$ & 223.6 \\
\hline Bark-peat (BP) & 4.5 & 0.09 & $21.8 \mathrm{~b}$ & 0.61 & 6.37 & 206.4 \\
\hline Bark-coir (BC) & $6.3^{*}$ & 0.06 & $32.5 \mathrm{a}^{*}$ & 0.71 & $8.59 *$ & 193.8 \\
\hline Pval $^{\mathrm{s}}$ & $\mathrm{x} 0.0188$ & 0.0992 & 0.0017 & 0.2442 & 0.0107 & 0.5749 \\
\hline
\end{tabular}

${ }^{\mathrm{z}}$ Water loss by substrate-plant system (excluding leaching) measured by lysimeter.

${ }^{\mathrm{y}}$ Water leached $\div$ water applied.

${ }^{\mathrm{x}}$ The difference in plant dry mass between initiation and culmination of the low substrate water potential production portion of this experimentation.

${ }^{\text {w}}$ Volume of water applied $\div$ time of production.

${ }^{\mathrm{v}}$ Measured as evapotranspiration $\div$ carbon acquisition over low water potential production.

${ }^{\mathrm{u}}$ Asterisk denotes detected differences between treatment and UB (control).

${ }^{t}$ Letters denote detected differences among means of three engineered substrates (FB, BP, and BC) using the Tukey's HSD ( $\left.\alpha=0.05\right)$.

${ }^{\mathrm{s}}$ Measures of overall treatment effects using analysis of variance. 
Table 5. Instantaneous measures of plant water relations for four experimental bark substrates. Substrates include a control (UB), bark particles $<4$ mm (FB), bark $>4 \mathrm{~mm}$ with $35 \%$ by vol. Sphagnum peatmoss (BP), and bark $>4 \mathrm{~mm}$ with $35 \%$ coir (BC). Data were measured on 17 and $32 \mathrm{~d}$ after initiation (DAI) of an experiment where substrate water potential was held between -100 and $-300 \mathrm{hPa}$. Data were measured with a portable photosynthesis meter (LI-COR 6400xt).

\begin{tabular}{|c|c|c|c|c|c|c|c|}
\hline \multirow[b]{3}{*}{ Substrate } & \multirow{2}{*}{\multicolumn{3}{|c|}{$17 \mathrm{DAI}$}} & \multicolumn{4}{|c|}{32 DAI } \\
\hline & & & & \multirow[b]{2}{*}{$\begin{array}{c}\text { Net } \\
\text { photosynthesis } \\
\left(\mathrm{mmol} \cdot \mathrm{m}^{-2} \cdot \mathrm{s}^{-1} \mathrm{CO}_{2}\right)\end{array}$} & \multirow[b]{2}{*}{$\begin{array}{c}\text { Stomatal } \\
\text { conductance } \\
\left(\mathrm{mol} \cdot \mathrm{m}^{-2} \cdot \mathrm{s}^{-1} \mathrm{H}_{2} \mathrm{O}\right)\end{array}$} & \multirow[b]{2}{*}{$\begin{array}{c}\text { Transpiration } \\
\left(\mathrm{mmol} \cdot \mathrm{m}^{-2} \cdot \mathrm{s}^{-1} \mathrm{H}_{2} \mathrm{O}\right)\end{array}$} & \multirow{2}{*}{$\begin{array}{c}\text { Stem } \\
\text { water } \\
\text { potential } \\
(-\mathrm{MPa})\end{array}$} \\
\hline & $\begin{array}{c}\text { Net } \\
\text { photosynthesis } \\
\left(\mathrm{mmol} \cdot \mathrm{m}^{-2} \cdot \mathrm{s}^{-1} \mathrm{CO}_{2}\right)\end{array}$ & $\begin{array}{c}\text { Stomatal } \\
\text { conductance } \\
\left(\mathrm{mol} \cdot \mathrm{m}^{-2} \cdot \mathrm{s}^{-1} \mathrm{H}_{2} \mathrm{O}\right)\end{array}$ & $\begin{array}{c}\text { Transpiration } \\
\left(\mathrm{mmol} \cdot \mathrm{m}^{-2} \cdot \mathrm{s}^{-1} \mathrm{H}_{2} \mathrm{O}\right)\end{array}$ & & & & \\
\hline$\overline{\text { Unprocessed (UB) }}$ & 3.62 & 0.0335 & 1.02 & 2.54 & 0.0472 & 1.12 & 1.41 \\
\hline Fines $(\mathrm{FB})$ & $9.99 * \mathrm{y}$ & 0.1421 & 3.35 & $7.08 *$ & $0.1206^{*}$ & $2.65^{*}$ & 1.03 \\
\hline Bark-peat (BP) & 5.13 & 0.0493 & 1.44 & 4.21 & 0.0589 & 1.38 & 1.10 \\
\hline Bark-coir (BC) & 8.13 & 0.0769 & 2.16 & 3.99 & 0.0859 & 1.99 & 1.15 \\
\hline Pval $^{\mathrm{x}}$ & 0.1196 & 0.2625 & 0.1840 & 0.1403 & 0.0719 & 0.0964 & 0.6043 \\
\hline$r-K_{200}{ }^{\mathrm{w}}$ & 0.6667 & 0.6131 & 0.6563 & 0.6656 & 0.7415 & 0.7123 & -0.3374 \\
\hline
\end{tabular}

${ }^{\mathrm{z}}$ Measured on apical stem consisting of three nodes immediately after severing, using a Model 600 pressure chamber (PMS Instruments).

${ }^{\mathrm{y}}$ Asterisk denotes difference detected between representative treatment and the control (UB) according to the Dunnett's test ( $\left.\alpha=0.05\right)$.

${ }^{\mathrm{x}}$ Measures of overall treatment effects using analysis of variance.

${ }^{\text {w}}$ Pearson's correlation constant between substrate hydraulic conductivity at water potential $=-200 \mathrm{hPa}$ and the metric being analyzed.

Table 6. Plant water uptake cutoff points for four experimental bark substrates. Substrates include a control (UB), bark particles $<4$ mm (FB), bark $>4$ mm with $35 \%$ by vol. Sphagnum peatmoss (BP), and bark $>4 \mathrm{~mm}$ with $35 \%$ coir (BC). Planted substrate watered to maximum water holding capacity and allowed to dry down until plant stopped withdrawing water from substrate.

\begin{tabular}{|c|c|c|c|c|}
\hline Substrate & Unprocessed (UB) & Fines $(\mathrm{FB})$ & Bark-peat (BP) & Bark-coir (BC) \\
\hline$\overline{\text { Water content }\left(\mathrm{m}^{3} \cdot \mathrm{m}^{-3}\right)^{\mathrm{z}}}$ & $0.126(0.120,0.133)^{\mathrm{y}}$ & $0.101(0.095,0.107)$ & $0.134(0.128,0.140)$ & $0.102(0.095,0.109)$ \\
\hline Water potential $(\mathrm{MPa})^{\mathrm{x}}$ & $0.09(0.07,0.10)$ & $0.11(0.09,0.13)$ & $0.32(0.25,0.39)$ & $0.37(0.29,0.47)$ \\
\hline $\operatorname{RMSE}^{\mathrm{w}}(\mathrm{g})$ & 16.79 & 28.04 & 22.57 & 21.68 \\
\hline
\end{tabular}

${ }^{\mathrm{z}}$ Values in parentheses represent a $95 \%$ confidence interval from the mean value.

${ }^{\mathrm{y}}$ Volumetric water content calculated at time of cessation of water withdrawal.

${ }^{\mathrm{x}}$ Substrate water potential using substrate moisture characteristic data modeled to Brooks and Corey model for conversions.

${ }^{\mathrm{w}}$ Root mean square error (RMSE) of the data points to the nonlinear to linear regression model, based on container system mass.

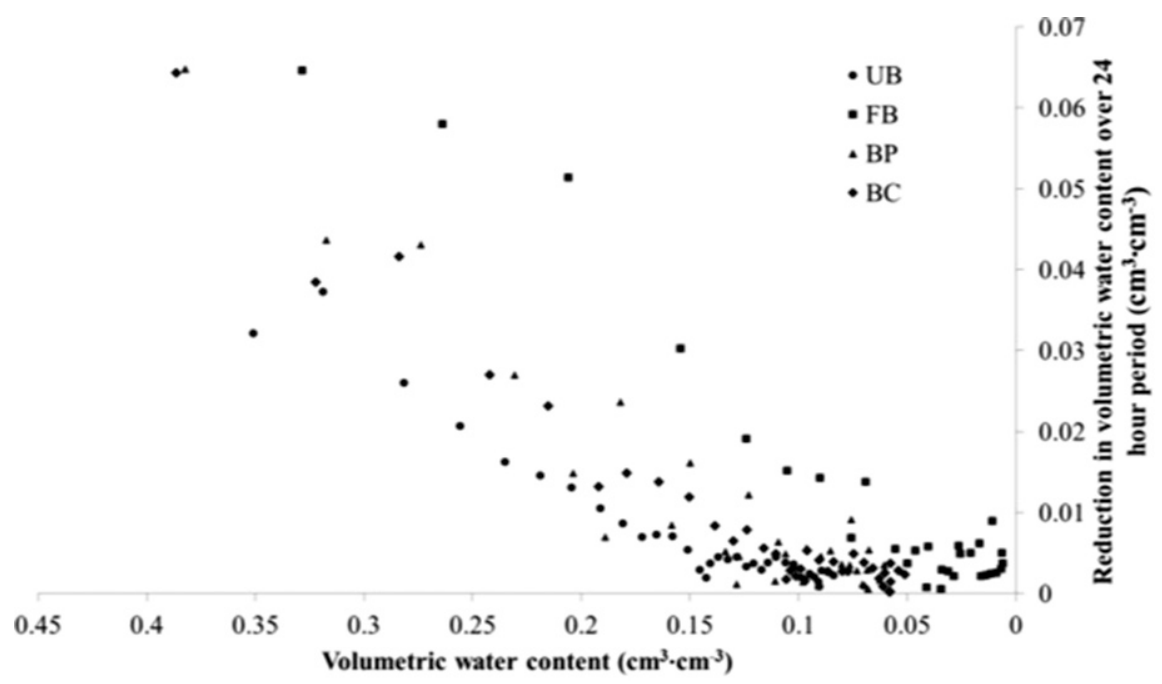

Fig. 5. The reduction in volumetric water content of four experimental pine bark-based substrates used to produce Hydrangea arborescens plants. Substrates included conventional pine bark (unprocessed bark, UB), bark particles that pass through a 4.0-mm screen (fine bark, FB), bark particles that do not pass through a $4.0-\mathrm{mm}$ screen while at $65 \%$ moisture content amended with fibrous materials including $35 \%$ Sphagnum peat (bark-peat, BP) and 35\% coir (bark-coir, BC) by volume. Substrates with fully rooted plants were watered to effective container capacity (maximum water holding capacity via spray stake irrigation) before allowing to dry past permanent wilt until the plant ceased withdrawing water from the substrate. Daily reduction in substrate volumetric water contents were plotted against volumetric water content for each substrate to illustrate at what volumetric water content evapotranspiration shifts to primarily evaporation due to plant water uptake diminishing.

hypothesized to be a result of increased growth and vigor (LA and GI), but could be an artifact of varying environmental conditions. Also, FB and BC grew faster and with increased vigor when compared with other plants, but the plants in BP were consuming the least water per carbon fixed at 32 DAI.

Instantaneous WUE was greatest in plants grown in PB at $32 \mathrm{DAI}$; however, this may have been a result of less developed plants grown in UB skewing measures (Fig. 4).
While all three engineered substrates (excluding UB) were capable of producing marketable crops at this $\Psi$ p (Fig. 4), the BC and $\mathrm{FB}$ produced marketable plants quicker than the $\mathrm{BP}$, reducing time to market. Because the difference in water per plant was not extreme and the leaching fractions (water wasted) was minimal across all treatments, it would likely be worth the added water inputs to push plants to marketable levels sooner, which in itself would reduce water consumption. The UB, which was within the BMP recommendations for physical properties, was unable to maintain proper hydration throughout the experimental portion of the study. We hypothesize that this is likely a result of reduced $K \mathrm{p}$, which we believe will become more critical as $\Psi$ is reduced in even drier production scenarios.

Plant available water. The plant used water in FB for $12.16 \mathrm{~d}$, after being irrigated to effective $\mathrm{CC}$ and water withheld, at which point water loss was primarily due to evaporation (Table 6). This was the least time for a plant to reach this point; however, this is likely a result of increased plant size. The plants in BP, BC, and UB followed in sequence. This timing follows similar sequences as $K_{200}$, aside from the reversal of $\mathrm{BP}$ and $\mathrm{BC}$, which is likely a result of an inverse relationship between $K$ of peat and coir additions at $\Psi>-100 \mathrm{hPa}$ (Fields, 2017). Therefore, since the plant experienced a wide range of $\Psi$ before ceasing water uptake, and over the entire $\Psi$, the $K$ of BP may be larger than $K$ of BC. The final GI and LA of the plants were also a major driver of time taken 
to reach the VWC that transpiration reduces and water loss was primarily driven by evaporation. However, since there was no difference in final GI between plants grown in $\mathrm{FB}$ and $\mathrm{BC}$, we hypothesize that the increased $K$ allows for the plants to absorb water from the substrate at a higher rate, consuming available water more readily.

The reductions in VWC over each $24 \mathrm{~h}$ period (from 0000 to $0000 \mathrm{HR}$ ) were plotted against the total VWC for the substrate (Fig. 5). These data show a clear switch to an asymptotic relationship at the same calculated VWC water uptake cutoff point. We observed that the UB and BP were at similar VWC when water loss transitioned from ET to evaporation $\left(\approx 13.0 \mathrm{~cm}^{3} \cdot \mathrm{cm}^{-3}\right)$. Plants in FB and BC also ceased water uptake at similar VWC $\left(10.1 \mathrm{~cm}^{3} \cdot \mathrm{cm}^{-3}\right.$; Table 6). The increased $K$ in the $\mathrm{FB}$ and $\mathrm{BC}$ may have allowed for more water to be removed; however, the slight difference between the four substrates may correspond with the lack of difference of final R:S, which has been known to indicate water availability (Harris, 1914). Further conversions of the VWC water uptake cutoff points, using MCC models, we see that the plants in the UB and FB ceased withdrawing water at $\Psi$ of $-0.10 \mathrm{MPa}$, and the plants in $\mathrm{BP}$ and $\mathrm{BC}$ were at $-0.35 \mathrm{MPa}$ when plants stopped removing water from the substrate. These values were much higher than we had hypothesized based on previous research (Fields, 2013), as none of the crops approached $\Psi$ of $-1.5 \mathrm{MPa}$. This is known to be a species-specific trait. $H y$ drangea sp. are known to flag, or readily wilt without continuous water during high temperatures (O'Meara et al., 2014). There was no correlation between $\Psi$ at which plants stopped absorbing water and $K_{-200}$ or $K_{\mathrm{s}}$. Conversely, the VWC point when water loss transitioned from ET to evaporation was correlated with $K_{200}(r=-0.78, P=$ 0.2232 ). Both these values are based on models and therefore based on low total data points $(n=4)$

\section{Conclusions}

Measurement of substrate $K \mathrm{p}$ was correlated with measured parameters of crop morphology and physiology, suggesting it is a meaningful metric for evaluating and comparing substrates. Substrate $K_{\mathrm{s}}$, while more commonly measured, is not correlated with $K \mathrm{p}$, nor strongly correlated with any physiological or morphological metric, and therefore, does not yield information that will help predict crop success as measured by growth and appearance. Furthermore, increased substrate $K \mathrm{p}$ will allow plants to access water not only to sustain vigor but also to produce marketable crops using less water. The increased $K$ p likely allows for quicker time to market for ornamental containerized crops. Crops can be produced with minimal water loss from leaching when specialized, engineered substrates with increased $K$ are used and irrigation is managed to hold crops at $\Psi$ between -100 and -300 . In addition, the low volumes of water the plant receives will provide growers with water savings during production. We also observed that lower production $\Psi$ did not enable plants to continue withdrawing water at low $\Psi$ unlike previous research and hypothesize that this is more of a species artifact. From previous research we understand that substrate $K$ is different over $\Psi$ ranges and therefore all substrates are not suitable for every $\Psi$ range. The coir fiber increases $K$ more than the peat fiber when at $\Psi<-100 \mathrm{hPa}$ and provides more AS which will benefit gas exchange if crops become over hydrated. The high percentage of fine particles in FB, which was designed for this irrigation scenario, produced high quality plants in this research. However, if used in traditionally irrigated systems or in production that includes precipitation, over hydration would likely occur, limiting gas exchange and deleteriously influencing crop vigor. Further research into the use of substrate $K$, VWC, and $\Psi$ relationships will lead to development of substrates that hold more sufficient when dry but continue to allow ample drainage readily when in higher moisture systems.

\section{Literature Cited}

Abad, M., F. Fornes, C. Carrion, V. Noguera, P. Noguera, A. Maquieira, and R. Puchades. 2005. Physical properties of various coconut coir dusts compared to peat. HortScience 40:2138 2144.

Abad, M., P. Noguera, R. Puchades, A. Maquieria, and V. Noguera. 2002. Physio-chemical and chemical properties of some coconut coir dusts for use as a peat substrate for containerized ornamental plants. Bioresour. Technol. 82:241245.

Bacon, M. 2004. Water use efficiency in plant biology. Blackwell Publishing Ltd., Oxford, ISBN 1-4051-1434-7.

Barrett, G.E., P.D. Alexander, J.S. Robinson, and N.C. Bragg. 2016. Achieving environmentally sustainable growing media for soilless plant cultivation systems-A review. Sci. Hort. 212:220-234.

Bayer, A., I. Mahbub, M. Chappell, J. Ruter, and M.W. van Iersel. 2013. Water use and growth of Hibiscus acetosella 'Panama Red' grown with a soil moisture sensor-controlled irrigation system. HortScience 48:980-987.

Beeson, R.C., Jr., M.A. Arnold, T.E. Bilderback, B Bolusky, S. Chandler, H.M. Gramling, J.D Lea-Cox, J.R. Harris, P.J. Klinger, H.M Mathers, J.M. Ruter, and T.H. Yeager. 2004. Strategic vision of container nursery irrigation in the next ten years. J. Environ. Hort. 22:113115.

Bilderback, T., C. Boyer, M. Chappell, G. Fain, D. Fare, C. Gilliam, B.E. Jackson, J. Lea-Cox, A.V. LeBude, A. Niemiera, J. Owen, J. Ruter, K. Tilt, S. Warren, S. White, T. Whitewell, R. Wright, and T. Yeager. 2013. Best management practices: Guide for producing nursery crops. Southern Nursery Association, Inc., Acworth, GA.

Brooks, R.H. and A.T. Corey. 1964. Hydraulic properties of porous media. Colorado State Univ., Hydro. Paper 5.

Bunt, A.C. 1961. Some physical properties of potplant composts and their effects on growth Plant Soil 13:322-332.
Campbell, G.S. and M.D. Campbell. 1982. Irrigation scheduling using soil moisture measurements: Theory and practice. Adv. Irr. 1:25-42.

Caron, J., S. Pepin, and Y. Periard. 2014. Physics of growing media in a green future. Acta Hort. 1034:309-317.

Caron, J., L.M. Riviere, and G. Guillemain. 2005. Gas diffusion and air-filled porosity: Effect of some oversize fragments in growing media. Can. J. Soil Sci. 85:57-65.

Chong, C., R.A. Cline, and D.L. Rinker. 1994. Bark- and peat-amended spent mushroom compost for containerized culture of shrubs. HortScience 29:781-784.

da Silva, F.F., R. Wallach, and Y. Chen. 1993. Hydraulic properties of sphagnum peat moss and tuff (scoria) and their potential effects on water availability. Plant Soil 154:119-126.

de Boodt, M. and O. Verdonck. 1972. The physical properties of substrates in horticulture. Acta Hort. 26:37-44.

Dirr, M.A. 2009. Manual of woody landscape plants: Their identification, ornamental characteristics, culture, propagation, and uses. 6th ed. Stipes Publishing LLC, Champaign, IL.

Fields, J.S. 2013. Hydrophysical properties and hydration efficiency of traditional and alternative greenhouse substrate components. North Carolina State Univ., Raleigh, NC, MS Diss.

Fields, J.S. 2017. Soilless substrate hydrology and subsequent impacts on plant-water relations of containerized crops. Virginia Tech, Blacksburg, VA, PhD Diss.

Fields, J.S., J.S. Owen, Jr., L. Zhang, and W.C. Fonteno. 2016. The use of the evaporative method for determination of soilless substrate moisture characteristic curves. Sci. Hort. 211:102-109.

Fonteno, W.C. and C.T. Harden. 2010. North Carolina State University horticultural substrates lab manual. North Carolina State Univ.

Fulcher, A. and T. Fernandez. 2013. Sustainable nursery irrigation management series: Part I. Water use in nursery production. Bulletin W287, Univ. of Tennessee.

Fulcher, A., A.V. LeBude, J.S. Owen, Jr., S.A. White, and R.C. Beeson. 2016. The next ten years: Strategic vision of water resources for nursery producers. HortTechnology 26:121-132.

Halcomb, M. and S. Reed. 2012. Hydrangea production. Univ. Ten. Coop. Ex. Serv.

Harris, F.S. 1914. The effect of soil moisture, plant food, and age on the ratio of tops to roots in plants. J. Amer. Soc. Agron. 6:65-75.

Hillel, D. 1998. Environmental soil physics. 2nd ed. Academic Press, San Diego, CA.

Hunt, A.G., R.P. Ewing, and R. Horton. 2013. What's wrong with soil physics? Soil Sci. Soc. Amer. J. 77:1877-1887.

Kenney, J.F., N.L. Barber, S.S. Hutson, K.S Linsey, J.K. Lovelace, and M.A. Maupan. 2009. Estimated use of water in the United States in 2005. US Geological Services circular 1344.

Klock-Moore, K.A. and T.K. Broschat. 2001 Effect of four growing substrates on growth of ornamental plants in two irrigation systems. HortTechnology 11:456-460.

Knox, G.W. and M. Chappell. 2014. Alternatives to petroleum-based containers for the nursery industry. Florida Coop. Ext. Serv. ENH1193.

LeBude, A.V. and T.E. Bilderback. 2009. Pourthrough extraction procedure: A nutrient management tool for nursery crops. North Carolina Coop. Ext. AG-717-W, 08/2009 BS.

Mathers, H.M., T.H. Yeager, and L.T. Case. 2005. Improving irrigation water use in container nurseries. HortTechnology 15:8-12. 
McCree, K.J. 1986. Whole plant carbon balance during osmotic adjustment to drought and salinity stress. Austral. J. Plant Physiol. 13:33-43.

Naasz, R., J.C. Michel, and S. Charpentier. 2005. Measuring hysteretic hydraulic properties of peat and pine bark using a transient method. Soil Sci. Soc. Amer. J. 69:13-22.

O’Meara, L., M.R. Chappell, and M.W. van Iersel 2014. Water use of Hydrangea macrophylla and Gardenia jasminoides in response to a gradually drying substrate. HortScience 49:493-498.

Pallardy, S.G. 2008. S.G. Pallardy (ed). Physiology of woody plants, 3rd ed. Elsevier, San Diego, CA.
Pokorny, F.A., P.G. Gibson, and M.G. Dunavent. 1986. Prediction of bulk density of pine bark and/or sand potting media from laboratory analyses of individual components. J. Amer. Soc. Hort. Sci. 111:8-11.

Pustjarvi, V. and R.A. Robertson. 1975. Physical and chemical properties. p. 23-38. In: Peat in horticulture. Academic Press, London, UK.

Raviv, M. and J.H. Lieth. 2008. Soilless culture theory and practice. Elsevier, San Diego, CA.

Raviv, M., R. Wallach, A. Silber, S. Medina, and A. Krasnovsky. 1999. The effect of hydraulic characteristics of volcanic materials on yield of roses grown in soilless culture. J. Amer. Hort. Sci. 124:205-209.

Scheiber, S. and R.C. Beeson. 2006. Petunia growth and maintenance in the landscape as influenced by alternative irrigation strategies. HortScience 41:235-238.

van Iersel, M.W. and K.S. Nemali. 2004. Drought stress can produce small but not compact marigolds. HortScience 39:1298-1301.

Vertessy, R.A., R.G. Benyon, K.S. O’Sullivan, and P.R. Gribben. 1995. Relationships between stem diameter, sapwood area, leaf area, and transpiration in a young mountain ash forest. Tree Physiol. 15:559-567. 